\title{
The effects of canola and olive oils consumption compared to sunflower oil, on lipid profile and hepatic steatosis in women with polycystic ovarian syndrome: a randomized controlled trial
}

\author{
Maryam Yahay ${ }^{1,2}$, Zahra Heidari ${ }^{3}$, Zahra Allameh ${ }^{4}$ and Reza Amani ${ }^{1,5^{*}}$ (D)
}

\begin{abstract}
Background: Polycystic Ovarian Syndrome (PCOS) is one of the most common endocrinopathies and metabolic disorders in women during their reproductive years. It is often associated with dyslipidemia and other risk factors of cardiovascular diseases (CVD). This study was aimed to evaluate dietary intervention effects with canola and olive oils compared to sunflower oil on lipid profile and fatty liver severity among women with PCOS.

Method: This study was a 10-week intervention including 72 women with PCOS. Patients were randomly assigned to three groups for receiving $25 \mathrm{~g} /$ day canola, olive, or sunflower oils for 10 weeks. The primary and secondary outcomes were to assess changes in lipid profile and in fatty liver severity, respectively.

Result: At the end of the study, 72 patients with a mean age of 29.31 were analysed. Canola oil consumption resulted in a significant reduction in serum levels of TG $(P=0.002)$ and TC/HDL $(P=0.021), L D L / H D L ~(P=0.047)$, and TG/HDL $(P=0.001)$ ratios, however, there was no significant reduction in lipid profile following olive oil consumption. Canola $(P<0.001)$ and olive oils $(P=0.005)$ could significantly reduce the fatty liver grade. Moreover, HOMA-IR in both canola $(P<0.001)$ and olive $(P=0.004)$ groups was significantly decreased.
\end{abstract}

Conclusion: In total, compared to olive and sunflower oils, significant improvements in lipid profile, liver function, and HOMA-IR were observed following canola oil consumption in women with PCOS.

Trial registration: IR.MUI.RESEARCH.REC.1397.315. Registered 30 JUNE 2019 - Retrospectively registered, https:// www.irct.ir/trial/38684

Keywords: Polycystic ovary syndrome, Canola oil, Olive oil, Lipid profile, Fatty liver, Polyunsaturated fatty acid, Monounsaturated fatty acid, HOMA-IR, SHBG

\footnotetext{
* Correspondence: r_amani@nutr.mui.ac.ir

'Nutrition and Food Sciences, Isfahan University of Medical Sciences, Isfahan,

Iran

${ }^{5}$ Food Security Research Center, Isfahan University of Medical Sciences,

Isfahan, Iran

Full list of author information is available at the end of the article
}

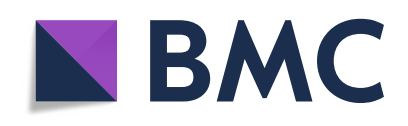

(c) The Author(s). 2021 Open Access This article is licensed under a Creative Commons Attribution 4.0 International License, which permits use, sharing, adaptation, distribution and reproduction in any medium or format, as long as you give appropriate credit to the original author(s) and the source, provide a link to the Creative Commons licence, and indicate if changes were made. The images or other third party material in this article are included in the article's Creative Commons licence, unless indicated otherwise in a credit line to the material. If material is not included in the article's Creative Commons licence and your intended use is not permitted by statutory regulation or exceeds the permitted use, you will need to obtain permission directly from the copyright holder. To view a copy of this licence, visit http://creativecommons.org/licenses/by/4.0/. The Creative Commons Public Domain Dedication waiver (http://creativecommons.org/publicdomain/zero/1.0/) applies to the data made available in this article, unless otherwise stated in a credit line to the data. 


\section{Introduction}

Polycystic Ovarian Syndrome (PCOS) is one of the most common endocrinopathies and metabolic disorders in women during their reproductive years [1, 2]. Regarding the study of Ding et al. (2017), in women with reproductive age, the PCOS prevalence was estimated from 5 to $18 \%$ which is higher in obese and diabetic women [3]. Considering Rotterdam criteria, this syndrome is characterized by symptoms such as hirsutism, oligomenorrhea, infertility, obesity, anovulation, and acne [4]. The syndrome's etiology is not precisely known, and researchers suggest a combination of genetic and environmental factors. Insulin Resistance (IR) is a typical characteristic of this syndrome which is found in $25-60 \%$ of women with PCOS [5]. One of the factors involved in PCOS etiology is oxidative stress which increases the levels of free radicals and results in elevated lipid peroxidation and insulin resistance [6]. On the other hand, various studies showed that women with polycystic ovary syndrome are at greater risk for chronic diseases, especially cardiovascular disease (CVD) [7-9]. Moreover, PCOS increases the risk of dyslipidemia. Dyslipidemia in PCOS is associated with prevalent insulin resistance, although, not all women with PCOS have IR [10]. Considering previous studies, dyslipidemia in PCOS has a multifactorial nature $[6,11]$. In a meta-analysis, researchers reported that women with PCOS have $26 \mathrm{mg} / \mathrm{dL}$ higher triglycerides, lower HDL-cholesterol, and higher non-HDL-cholesterol levels compared with their non-PCOS counterparts [12]. Nutritional management has a key role in obesity, hepatic steatosis, and other metabolic pathologies [13]. Studies showed that dietary fatty acid patterns could exert important effects on PCOS related complications, including obesity, imbalanced glycemic and hormonal homeostasis, inflammation, and dysregulation of adipokine production $[14,15]$. Replacing saturated fatty acids (SFAs) with polyunsaturated fatty acids (PUFAs) can reduce insulin resistance resulting in improved lipid profile $[16,17]$. Moreover, PUFAs consumption has various beneficial effects on chronic disorders [18, 19]. Hence, omega-3 PUFAs, as mainly eicosapentaenoic acid (EPA) and docosahexaenoic acid (DHA) are substrates for signaling molecules regulating the liver lipid metabolism and enhanced the lipid profile $[20,21]$. This feature is achieved through (i) transcriptional activation of FA oxidation by peroxisome proliferator-activated receptor alpha (PPAR- $\alpha$ ); and (ii) suppression of de novo lipogenesis via down-regulation of sterol regulatory elementbinding protein 1 (SREBP-1c) [13, 22]. Some studies showed that women can significantly convert alphalinolenic acid (ALA) into EPA and DHA compared to men, with estimated net conversion rates of ALA to EPA of $21 \%$ vs. $8 \%$ and of ALA to DHA of $9 \%$ vs. $0 \%$, respectively [23, 24]. Women also have a higher concentration of serum DHA [25]. Besides, decreased n6/n3 PUFA ratio may be correlated to an augment of $\Delta 5$ - and $\Delta 6$-desaturase activity and consequently more conversion of ALA to omega-3 fatty acids, especially EPA [26, 27].

Canola oil is a rich source of PUFAs, especially linoleic acid, alpha-linolenic acid (ALA), and mono-unsaturated fatty acids (MUFAs) [28]. Olive oil is one of the Mediterranean diet main components that is rich in MUFAs and dietary polyphenols [29]. Although canola and olive oils have higher MUFAs, ALA is higher, and n6/n3 PUFA ratio is lower in canola oil; therefore, it appears to be a healthier choice [30].

Previous studies showed positive effects of olive and canola oils in dyslipidemia modulation [31-33]. Moreover, dietary patterns with a higher amount of PUFAs and MUFAs have beneficial effects including antiatherogenic and anti-inflammatory actions which can improve non-alcoholic fatty liver disease (NAFLD) severity [34, 35].

Homeostasis model evaluation for insulin resistance index (HOMA-IR) is the most highly utilized marker among static IR indices as a surrogate measurement of IR in large population researches. Thus, studies surveying the prevalence of IR in PCOS are greatly inconsistent mainly based on different methods applied and cut-offs chosen to define IR [36-38]. Furthermore, an ongoing debate is present whether IR in PCOS is due to obesity alone or obesity aggravates IR intrinsic to PCOS [39, 40].

Sex hormone-binding globulin (SHBG) is expressed in the human liver under controlling the hormones and nutritional factors [41]. The human liver secretes SHBG into the blood, where it binds to androgens and estrogens with high affinity, regulating their bioavailability. BMI is considered the main determinant of circulating SHBG concentrations, and a negative correlation between BMI and SHBG plasma levels was consistently reported [42].

Therefore, liver fat content rather than total body or visceral fat has been reported as the main determinant of circulating SHBG [43, 44]. Low serum SHBG concentrations in overweight individuals are a biomarker for metabolic syndrome $[45,46]$ and are predictive of type 2 diabetes (T2D) [47, 48] and CVD risk [49-51].

Furthermore, SHBG plays a central role in PCOS pathophysiology [52]. SHBG binds to testosterone with high affinity, hence, regulating free testosterone levels [53]. Circulating SHBG concentrations are characteristically low in patients with PCOS. These women have elevated androgen levels in which IR is present. Compensatory hyperinsulinemia and IR inhibit the hepatic synthesis and secretion of SHBG [54]. Hyperinsulinemia can increase androgen and free androgen 
production by reducing androgen binding with SHBG. Overall, these hormonal imbalances can progress to metabolic and cardiovascular diseases [55].

Despite the significant role of edible oils on lipid profile and considering significant discrepancies in research findings there is no clinical trial that has compared the effects of canola and olive oils on PCOS women. Due to the appropriate fatty acid content of canola and olive oils and since sunflower oil is one of the most common and cheapest edible oils in most areas, the present study was designed to evaluate the effects of these three oils on lipid profile, fatty liver, HOMA-IR and SHBG in women with PCOS.

\section{Materials and methods}

\section{Study design and patients' characteristics}

This study was conducted as a randomized, doubleblind, controlled clinical trial that conformed to Helsinki's declaration and Good Clinical Practice Guidelines. The study's protocol was reviewed and approved by Medical Ethics Committee at the Isfahan University of the Medical Sciences, Iran (ethics registration number: IR.MUI.RESEARCH.REC.1397.315) which was registered at the Iranian Registry of Clinical Trials (approval code: 38684). The participants included 90 patients with PCOS aged 18 to 45 years. Eligible patients were those with PCOS who were referred to gynecology clinics in Isfahan. Participants were included based on Rotterdam criteria [56] in which two following features were confirmed: 1) Oligomenorrhea (the interval between two menstrual periods more than 35 days) or amenorrhea (no vaginal bleeding for at least 6 months); 2) Clinical findings of increased blood androgen levels (hirsutism scores greater than 7 or obvious acne), or increased blood testosterone levels (testosterone levels above 2 $\mathrm{nmol} / \mathrm{L})$ and 3) Polycystic ovaries in ultrasound scan (12 follicles measuring $2-9 \mathrm{~mm}$ in diameter, or ovarian volume $>10 \mathrm{~mL}$ in at least one ovary). Patients were eligible if they had not taken any fat-lowering or omega- 3 supplements in the last 3 months. Furthermore, if they were not menopausal, and not following a special diet, having BMI between 25 and $<40$, and not having a severe weight loss history in the last 6 months. Participants were excluded if they had the following conditions: pregnancy, adrenal hyperplasia, androgen-secreting tumors, Cushing syndrome, hyperprolactinemia, thyroid dysfunction, diabetes or other metabolic diseases, using lipidlowering medications, tamoxifen, raloxifene, oral or injectable corticosteroids, any history of intolerance to the canola and olive oils. Moreover, patients who underwent chemotherapy and smoked were excluded. All participants were given the necessary explanations regarding the study protocol, and they completed written informed consent forms before commencing the study.

\section{Sample size}

The sample size was calculated based on the standard formula for clinical trials, regarding the type 1 error $(\alpha)$ of .05 and type 2 error $(\beta)$ of 10 (power $=90 \%$ ) considering serum TG levels in the study of Salar et al. [57]. Accordingly, 27 subjects were calculated for each treatment group. Considering three probable dropouts in each group, the final sample size of 30 individuals in each group was obtained.

\section{Fatty acid compositions of the oils}

Fatty Acids (FA) composition of refined olive, canola, and sunflower oils (Oila, Isfahan, Iran) were evaluated at the reference food chemistry laboratory (Meyar Danesh Pars laboratory, Isfahan, Iran). FA composition of the three oils was determined using high-performance gas chromatography [57]. Olive oil contained $68.93 \%$ oleic acid as the main FA while canola oil contained 59.62\% as oleic acid and $7.37 \%$ as ALA. Sunflower oil contained $60.51 \%$ linoleic acid as its main FA. Also, the n-6/n-3 ratio was 184 for sunflower oil, 17.8 for olive oil, and 2.9 for canola oil (Table 1).

\section{Randomization and intervention}

Patients were randomly assigned to the three equal groups to receive either $25 \mathrm{~g}$ canola or olive oils as the main intervention groups and the control group consumed $25 \mathrm{~g}$ sunflower oil daily for 10 weeks. The random allocation was done by an investigator who was not directly involved in the trial. Participants were given the oils in similar bottles. Neither participants nor the researchers and physicians were aware of the type of oils consumed to the end of the study. Bottles with the oils were given to the women for the first 5 weeks at the beginning of the study, and it was repeated in the next 5 weeks. Also, a small container was provided which exactly contained $25 \mathrm{~g}$ to pour the oil they needed every day. Women were asked to add oil to their salads or

Table 1 Fatty acid composition of three oils studied ${ }^{a}$

\begin{tabular}{lllll}
\hline Variable & & Sunflower oil & Canola oil & Olive oil \\
\hline SFA (\%) & Palmitic Acid & 6.75 & 5.55 & 13.78 \\
& Stearic Acid & 3.18 & 2.42 & 3.09 \\
& TOTAL & 11.39 & 9.26 & 17.55 \\
N-9 MUFA (\%) & Oleic Acid & 27.52 & 59.62 & 68.93 \\
& TOTAL & 27.70 & 61.39 & 69.22 \\
N-6 PUFA (\%) & Linoleic Acid & 60.51 & 21.21 & 11.13 \\
& TOTAL & 60.71 & 21.31 & 11.20 \\
N-3 PUFA (\%) & Linolenic Acid & 0.09 & 7.23 & 0.63 \\
& TOTAL & 0.33 & 7.37 & 0.63 \\
n-6/n-3 PUFA & & 183.96 & 2.89 & 17.77 \\
\hline
\end{tabular}

${ }^{\mathrm{a}}$ MUFA Monounsaturated Fatty Acid, SFA saturated fatty acid 
meals after cooking (e.g., rice, stew, etc.) so that the oil was not exposed to heat. All patients were advised to take a balanced diet with a macronutrient distribution of $45-60 \%$ as carbohydrate, 30 to $35 \%$ as fat, and $15-18 \%$ as protein. The diet was described and each woman was given an exchange list to ensure diet consistency during the 10-week intervention. Subjects were advised to limit fish and nuts intake (walnuts and fish at most once a week), and avoid taking omega-3 or flaxseed supplements. Also, all patients were asked not to change their physical activity patterns through the study. Participants were followed via short text messages and phone calls to detect any possible adverse effects. The compliance rate was determined by the number of empty bottles returned; those who consumed $85 \%$ of oils or more were considered as an adherent to the study.

\section{Anthropometric data and dietary intake}

The weight and body composition of the participants were evaluated by portable TANITA M780 (Tanita, Japan), and the height was measured by Seca 763 scale (Hamburg, Germany). Without shoes in a standing position, the weight was measured with light clothes. Height was measured in a standing position, looking straight ahead, arms at sides, and shoulders relaxed with no shoes on with $0.1 \mathrm{~cm}$ precision. Then, BMI was calculated by dividing the weight $(\mathrm{kg})$ by the square of height $\left(\mathrm{m}^{2}\right)$. A trained nutritionist evaluated the participants' dietary intake by a three-day food record questionnaire. Patients were asked to complete three-day food record questionnaires (two consecutive days and a day-off) at the beginning and end of the study. Then, all food items were entered into a customized Nutritionist IV software (1997, First Databank Inc., San Bruno, CA), and mean intake of energy, macro and micronutrients were calculated at the baseline and 10-week post-intervention.

\section{Physical activity assessment}

Participants filled in a validated form of the 7-item International Physical Activity Questionnaire (IPAQ) pre-and post-intervention. Data were converted to metabolic equivalent hour/week [58].

\section{Laboratory data}

The blood samples were obtained from all participants after $12 \mathrm{~h}$ of fasting. Blood samples were centrifuged at $3000 \mathrm{rpm}$ for $10 \mathrm{~min}$. Separated serums were frozen at $80^{\circ} \mathrm{C}$ until further biochemical measurements. Serum concentrations of TG, HDL-c, LDL-c, and total cholesterol were measured using an enzymatic colorimetric method (Pars Azmoon, Tehran, Iran). Non-HDL cholesterol was calculated by subtracting HDL-c from TC and represented LDL-c + IDL-c + VLDL-c cholesterol fractions [59]. The SHBG levels were measured using an enzyme-linked immunosorbent assay (IMMULITE 2000 SHBG).

At the beginning and end of the study, liver sonography was performed by a skilled radiologist for all patients using an ultrasound device (General Electric LOGIQ E9- using probe $3.5 / 5 \mathrm{MHz}$, USA). The radiologist was blind to the study process and study groups. A rating method was introduced to achieve a semiquantitative measure of the extent of fat deposition in the liver. Based on liver echo-texture parameters, the brightness of the liver, the contrast ratio of liver-tokidney, and blurred vessels, the degree of hepatic fatty infiltration was scored from grades 0 to 3 .

Fasting serum glucose (FSG) and serum insulin (FSI) were measured using spectrophotometry and radioimmunoassay (IMMULITE 2000 Insulin), respectively. Then, HOMA-IR was calculated using the following formula for each participant $[60,61]$ :

HOMA-IR $=($ FSG $\times$ FSI $) / 405$.

\section{Statistical analysis}

SPSS software version 21 (IBM Corp. IBM SPSS Statistics for Windows, Armonk, NY) was used to analyze data. Kolmogorov-Smirnov test evaluated the normality quantitative data. Data were presented as mean \pm standard deviation (SD) for quantitative variables and frequency (\%) for categorical variables. A Chi-square test was applied to analyze qualitative variables. The changes of quantitative variables were compared pre-and postintervention using a paired sample t-test. The baseline characteristics of participants were compared between the groups by independent samples t-test or Chi-Square test. One-way analysis of variance (ANOVA) and LSD post-hoc tests was used to compare the groups in terms of quantitative variables. Also, the covariance analysis (ANCOVA) was used to adjust the effect of confounding variables. $P$-value $<0.05$ was statistically considered significant.

\section{Results \\ Study baseline characteristics}

Totally, 72 participants (80\%) with a mean age of $29.31 \pm 6.52$ completed the trial. Eighteen participants (six in each group) failed to follow the protocol (Fig. 1). The participants' baseline characteristics are presented in Table 2. There were no significant differences between the three groups in age, height, weight, disease duration, physical activity, marital status, taking OCP, and metformin at the baseline and last 3 months.

\section{Dietary intake of participants}

Table 3 summarizes the macronutrients and micronutrients intake of participants. Statistical analysis of energy, macronutrients, and dietary intake of PUFA, SFA, LA, 


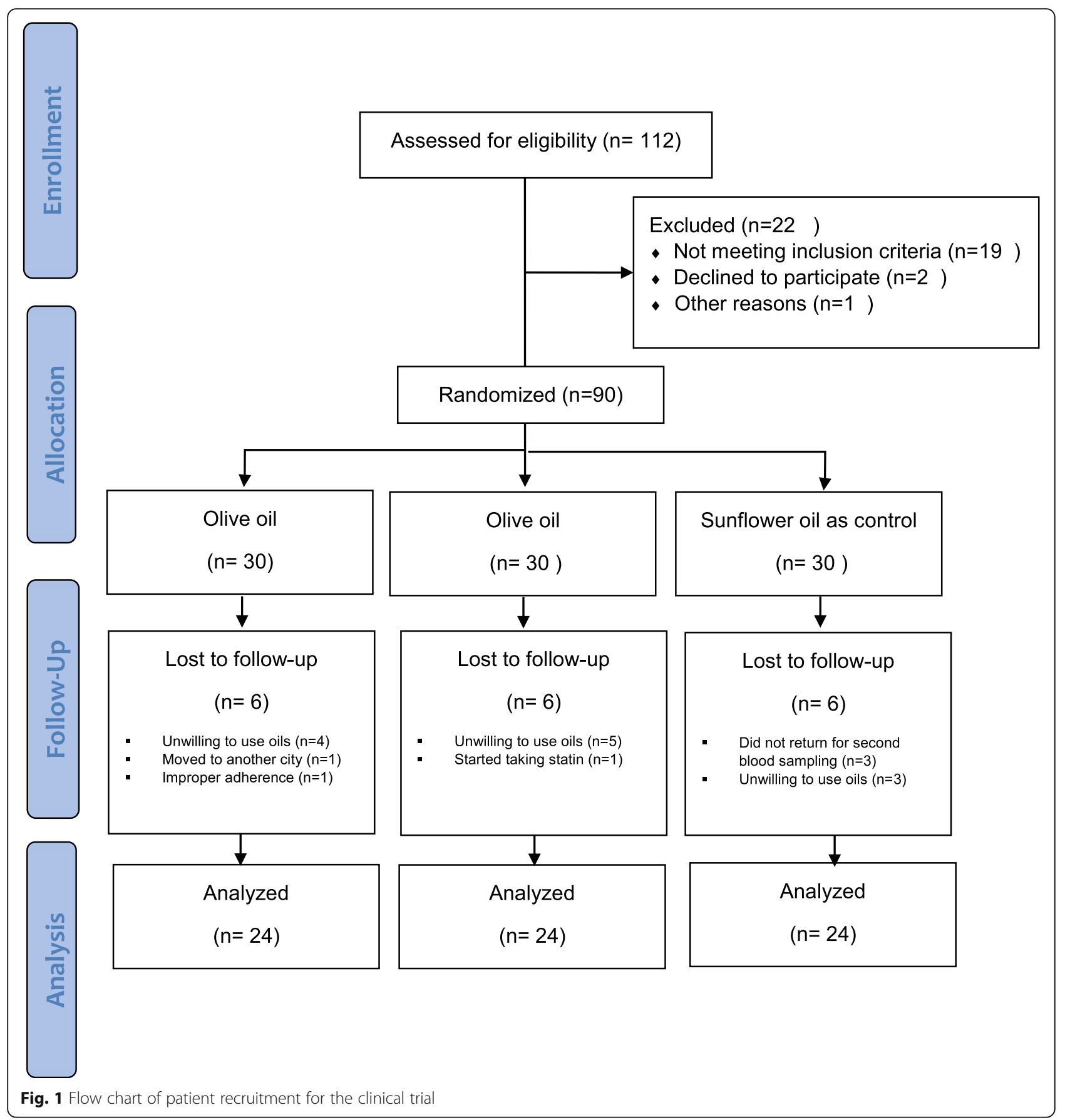

and dietary fiber showed no significant differences between the three groups at baseline and end of the study. However, at the end of the study, the dietary intake of MUFA was significantly higher in canola and olive oils groups $(P<0.001)$. Also, dietary intake of ALA was significantly increased in the canola oil group $(P<0.001)$.

\section{The effect of canola and olive oil on lipid profile}

Table 4 compares the lipid profile, HOMA-IR, and SHBG among canola, olive, and sunflower groups at the baseline and following 10 weeks of the study. At the beginning of the study, no significant differences were observed among the three groups in terms of lipid profile variables. After 10 weeks of intervention, there was a significant reduction in serum TG $(P=0.012)$, non-HDL-c $(P=0.014)$, TC/HDL-c $(P=0.007)$, LDL-c/HDL-c $(P=$ $0.040)$, and TG/HDL-c $(P=0.006)$ in the canola group. HOMA-IR in the canola group $(P<0.001)$ and in the olive group $(P=0.004)$ significantly declined. Also, a significant marginal drop in serum TC $(P=0.076)$ and 
Table 2 Baseline characteristics of the participants ${ }^{\text {a }}$

\begin{tabular}{|c|c|c|c|c|c|}
\hline \multicolumn{2}{|l|}{ variable } & sunflower oil group $(n=24)$ & canola oil group $(n=24)$ & olive oil group ( $n=24)$ & $P_{-}$value $^{*}$ \\
\hline \multicolumn{2}{|l|}{ Age (years) } & $28.08(6.17)$ & $31.75(6.35)$ & $29.58(7.26)$ & 0.163 \\
\hline \multicolumn{2}{|l|}{ Weight (kg) } & $80.07(12.97)$ & $71.95(7.14)$ & $73.97(12.47)$ & 0.038 \\
\hline \multicolumn{2}{|l|}{ BMI $\left(\mathrm{kg} / \mathrm{m}^{2}\right)$} & $29.47(3.57)$ & $27.74(1.91)$ & $28.84(4.44)$ & 0.127 \\
\hline \multicolumn{2}{|l|}{ Duration of PCOS (years) } & $2[1-4.74]$ & $2[0.31-9.5]$ & $5[1-9]$ & 0.434 \\
\hline \multicolumn{2}{|l|}{ Physical Activity (Met-Hours/wk) } & $19.69(23.54)$ & $17.37(24.97)$ & $14.17(16.27)$ & 0.689 \\
\hline \multirow[t]{2}{*}{ Marital } & Single & $5(20.8 \%)$ & $2(8.3 \%)$ & $4(16.7 \%)$ & \multirow[t]{2}{*}{0.472} \\
\hline & married & $19(79.2 \%)$ & $22(91.7 \%)$ & $20(83.3 \%)$ & \\
\hline \multirow{2}{*}{$\begin{array}{l}\text { OCP prescription } \\
\text { (last } 3 \text { months) }\end{array}$} & YES & $5(20.8 \%)$ & $5(20.8 \%)$ & $5(20.8 \%)$ & \multirow[t]{2}{*}{1.00} \\
\hline & NO & $19(79.2 \%)$ & $19(79.2 \%)$ & $19(79.2 \%)$ & \\
\hline \multirow[t]{2}{*}{ Metformin prescription (last 3 months) } & YES & $2(8.3 \%)$ & $2(8.3 \%)$ & $3(12.5 \%)$ & \multirow[t]{2}{*}{0.85} \\
\hline & NO & $22(91.7 \%)$ & $22(91.7 \%)$ & $21(87.5 \%)$ & \\
\hline
\end{tabular}

OCP Oral contraceptive pill, PCOS Polycystic ovary syndrome

${ }^{a}$ Values are mean (SD) or Median [Q1-Q3] or Number (percent)

* $P$-values are resulted from ANOVA or Chi-Square or kruskal-wallis test

LDL-c $(P=0.055)$ levels in canola oil was seen at the end. Canola oil supplementation caused a significant reduction in serum levels of TG $(P=0.004)$, and TC/HDLc $(P=0.021)$, LDL-c/HDL-c $(P=0.047)$, TG/HDL-c $(P=$ $0.001)$ and HOMA-IR $(P<0.001)$ indices compared to olive and sunflower oils. The changes were significant after adjusting the confounding factors (Table 4).

Within- and between-group changes in fatty liver severity are summarized in Table 5 . In within-group comparisons, fatty liver severity was significantly reduced in canola $(P<0.001)$ and olive $(P=0.005)$ groups, while no changes in the control group were evident. Moreover, there were no significant differences between canola and olive oil groups regarding fatty liver severity reduction $(P=0.404)$. Furthermore, the SHBG levels did not change significantly in all groups post-intervention.

Table 3 Comparison of dietary intake between the groups at the baseline and following intervention ${ }^{2}$

\begin{tabular}{|c|c|c|c|c|c|c|c|c|c|c|c|c|c|}
\hline \multirow[t]{2}{*}{ Variable } & \multicolumn{4}{|c|}{ sunflower oil group $(n=24)$} & \multicolumn{4}{|c|}{ canola oil group $(n=24)$} & \multicolumn{4}{|c|}{ olive oil group $(n=24)$} & \multirow{2}{*}{$\begin{array}{l}\text { P- } \\
\text { value** }\end{array}$} \\
\hline & before & after & Change & $\begin{array}{l}P \text { - } \\
\text { value* }\end{array}$ & before & after & change & $\begin{array}{l}P \text { - } \\
\text { value* }\end{array}$ & before & after & change & $\begin{array}{l}P \text { - } \\
\text { value* }\end{array}$ & \\
\hline Energy (kcal) & $\begin{array}{l}2056.62 \\
(390.05)\end{array}$ & $\begin{array}{l}1883.73 \\
(278.78)\end{array}$ & $\begin{array}{l}- \\
172.89\end{array}$ & .013 & $\begin{array}{l}2184.57 \\
(276.26)\end{array}$ & $\begin{array}{l}1947.40 \\
(357.62)\end{array}$ & $\begin{array}{l}- \\
237.17\end{array}$ & .001 & $\begin{array}{l}2076.89 \\
(352.01)\end{array}$ & $\begin{array}{l}1951.6 \\
(325.45)\end{array}$ & $\begin{array}{l}- \\
125.24\end{array}$ & .000 & 0.947 \\
\hline $\begin{array}{l}\text { Carbohydrate } \\
\text { (g) }\end{array}$ & $\begin{array}{l}323.44 \\
(78.88)\end{array}$ & $\begin{array}{l}262.73 \\
(60.07)\end{array}$ & -60.71 & .003 & $\begin{array}{l}297.70 \\
(58.49)\end{array}$ & $\begin{array}{l}238.49 \\
(81.75)\end{array}$ & -59.21 & .001 & $\begin{array}{l}312.85 \\
(62.54)\end{array}$ & $\begin{array}{l}287.81 \\
(54.40)\end{array}$ & -25.04 & .035 & 0.077 \\
\hline Protein (g) & $\begin{array}{l}75.83 \\
(19.99)\end{array}$ & $\begin{array}{l}79.33 \\
(25.16)\end{array}$ & 3.50 & .528 & $\begin{array}{l}77.84 \\
(26.95)\end{array}$ & $\begin{array}{l}83.12 \\
(18.54)\end{array}$ & 5.28 & .264 & $\begin{array}{l}73.32 \\
(12.66)\end{array}$ & $\begin{array}{l}81.86 \\
(15.07)\end{array}$ & 8.54 & .010 & 0.771 \\
\hline Fat (g) & $\begin{array}{l}55.35 \\
(22.18)\end{array}$ & $\begin{array}{l}66.82 \\
(25.43)\end{array}$ & 11.46 & .086 & $\begin{array}{l}62.96 \\
(19.42)\end{array}$ & $\begin{array}{l}82.63 \\
(24.00)\end{array}$ & 19.67 & .002 & $\begin{array}{l}60.08 \\
(16.89)\end{array}$ & $\begin{array}{l}73.51 \\
(26.65)\end{array}$ & 13.42 & .006 & 0.318 \\
\hline SFA (g) & $\begin{array}{l}18.36 \\
3.67))\end{array}$ & $\begin{array}{l}17.83 \\
(5.34)\end{array}$ & -0.53 & .643 & $\begin{array}{l}20.53 \\
(5.45)\end{array}$ & $\begin{array}{l}16.49 \\
(5.02)\end{array}$ & -4.03 & .014 & $\begin{array}{l}16.55 \\
(4.57)\end{array}$ & $\begin{array}{l}18.88 \\
(6.02)\end{array}$ & 2.32 & .018 & 0.275 \\
\hline PUFA (g) & $\begin{array}{l}18.36 \\
7.31))\end{array}$ & $\begin{array}{l}18.46 \\
(7.43)\end{array}$ & 0.10 & .875 & $\begin{array}{l}22.26 \\
(5.07)\end{array}$ & $\begin{array}{l}19.59 \\
(5.56)\end{array}$ & -2.67 & .003 & $\begin{array}{l}20.87 \\
(6.93)\end{array}$ & $\begin{array}{l}18.94 \\
(5.90)\end{array}$ & -1.92 & .023 & 0.089 \\
\hline MUFA(g) & $\begin{array}{l}13.47 \\
4.87))\end{array}$ & $\begin{array}{l}13.19 \\
(4.41)\end{array}$ & -0.27 & .644 & $\begin{array}{l}13.74 \\
(4.26)\end{array}$ & $\begin{array}{l}18.91 \\
(3.39)\end{array}$ & 5.17 & .000 & $\begin{array}{l}14.71 \\
(3.21)\end{array}$ & $\begin{array}{l}18.004 \\
(2.86)\end{array}$ & 3.28 & .000 & $<0.001$ \\
\hline $\mathrm{LA}(\mathrm{g})$ & $\begin{array}{l}16.40 \\
9.59))\end{array}$ & $\begin{array}{l}16.03 \\
(8.24)\end{array}$ & -0.37 & .854 & $\begin{array}{l}21.85 \\
(7.72)\end{array}$ & $\begin{array}{l}17.58 \\
(7.11)\end{array}$ & -4.26 & .016 & $\begin{array}{l}19.04 \\
(11.59)\end{array}$ & $\begin{array}{l}15.87 \\
(7.05)\end{array}$ & -3.17 & .145 & 0.816 \\
\hline ALA (g) & $130.09) 0)$ & $0.13(0.08)$ & 0.002 & .932 & $0.14(0.08)$ & $0.27(0.07)$ & 0.13 & .000 & $0.14(0.07)$ & $\begin{array}{l}0.14 \\
(0.13)\end{array}$ & 0.005 & .851 & 0.000 \\
\hline $\begin{array}{l}\text { Dietary } \\
\text { fiber(g) }\end{array}$ & $\begin{array}{l}18.48 \\
6.76))\end{array}$ & $\begin{array}{l}18.57 \\
(5.81)\end{array}$ & 0.10 & .928 & $\begin{array}{l}16.90 \\
(6.08)\end{array}$ & $\begin{array}{l}17.52 \\
(5.53)\end{array}$ & 0.61 & .431 & $\begin{array}{l}18.92 \\
(4.98)\end{array}$ & $\begin{array}{l}19.75 \\
(7.05)\end{array}$ & 0.82 & .549 & 0.812 \\
\hline
\end{tabular}

${ }^{a}$ ALA Alpha-linolenic acid, LA Linoleic acid, SFA saturated fatty acid, PUFA Polyunsaturated fatty acid, MUFA Monounsaturated fatty acid *P-values are resulted from paired samples t-test. ${ }^{* *} P$-values are resulted from ANCOVA, adjusted for baseline 
Table 4 Comparison of serum lipid profile, HOMA-IR and SHBG between the groups at the baseline and following intervention ${ }^{\text {a }}$

\begin{tabular}{|c|c|c|c|c|c|c|}
\hline Variable $^{\mathbf{b}}$ & & Sunflower $(n=24)$ & canola $(n=24)$ & Olive $(n=24)$ & $P^{*}$ & $P$ - adjusted ${ }^{* *}$ \\
\hline \multirow[t]{4}{*}{$\mathrm{TG}(\mathrm{mg} / \mathrm{dL})$} & Baseline & $140.08(81.04)$ & $140.38(42.22)$ & $121.78(64.93)$ & 0.37 & 0.66 \\
\hline & 10th wk. & 143.37 (64.46) & 134.33 (33.09) & 122.61 (59.66) & 0.03 & 0.04 \\
\hline & Changes & 3.29 & -6.08 & 0.82 & 0.004 & 0.002 \\
\hline & $P^{* * *}$ & 0.112 & 0.012 & 0.522 & & \\
\hline \multirow[t]{4}{*}{$\mathrm{TC}(\mathrm{mg} / \mathrm{dL})$} & Baseline & $177.29(38.31)$ & $188.50(34.23)$ & $180.21(31.89)$ & 0.136 & 0.265 \\
\hline & 10th wk. & $178.20(39.45)$ & $175.46(35.98)$ & $177.79(29.27)$ & 0.35 & 0.412 \\
\hline & Changes & 0.91 & -13.04 & -2.41 & 0.876 & 0.91 \\
\hline & $P^{* * *}$ & 0.83 & 0.076 & 0.778 & & \\
\hline \multirow[t]{4}{*}{ LDL (mg/dL) } & Baseline & 109.21 (32.59) & $121.71(29.45)$ & 116.35 (27.56) & 0.32 & 0.47 \\
\hline & 10th wk. & $114.46(32.24)$ & $109.63(31.54)$ & $111.48(23.63)$ & 0.512 & 0.563 \\
\hline & Changes & 5.25 & -12.08 & -4.87 & 0.276 & 0.36 \\
\hline & $P^{* * *}$ & 0.203 & 0.055 & 0.387 & & \\
\hline \multirow[t]{4}{*}{$\mathrm{HDL}(\mathrm{mg} / \mathrm{dL})$} & Baseline & $40.83(6.96)$ & $40.68(9.35)$ & $39.82(9.18)$ & 0.22 & 0.26 \\
\hline & 10th wk. & $40.29(7.70)$ & $41.27(9.09)$ & $39.39(9.45)$ & 0.49 & 0.52 \\
\hline & Changes & -0.54 & 1.37 & -0.75 & 0.353 & 0.391 \\
\hline & $P^{* * *}$ & 0.168 & 0.425 & 0.38 & & \\
\hline \multirow[t]{4}{*}{ Non-HDL (mg/dL) } & Baseline & $136.46(42.24)$ & $148.29(31.09)$ & $140.26(33.65)$ & 0.64 & 0.94 \\
\hline & 10th wk. & $137.92(43.05)$ & $133.88(33.42)$ & $135.70(29.82)$ & 0.32 & 0.46 \\
\hline & Changes & 1.45 & -14.41 & -4.56 & 0.144 & 0.239 \\
\hline & $P^{* * *}$ & 0.735 & 0.014 & 0.99 & & \\
\hline \multirow[t]{4}{*}{$\mathrm{TC} / \mathrm{HDL}$} & Baseline & $4.59(1.82)$ & $4.85(0.97)$ & $4.59(1.29)$ & 0.07 & 0.16 \\
\hline & 10th wk & $4.74(2.18)$ & $4.34(1.03)$ & $4.53(1.19)$ & $<0.001$ & $<0.001$ \\
\hline & Changes & 0.15 & -0.51 & -0.06 & 0.021 & 0.04 \\
\hline & $P^{* * *}$ & 0.397 & 0.007 & 0.765 & & \\
\hline \multirow[t]{4}{*}{ LDL/HDL } & Baseline & $2.72(1.13)$ & $3.13(0.82)$ & $2.94(0.93)$ & 0.89 & 0.89 \\
\hline & 10th wk & $2.83(1.08)$ & $2.70(0.85)$ & $2.89(0.88)$ & 0.05 & 0.007 \\
\hline & Changes & 0.11 & -0.43 & -0.05 & 0.047 & 0.049 \\
\hline & $P^{* * *}$ & 0.116 & 0.040 & 0.696 & & \\
\hline \multirow[t]{4}{*}{ TG/HDL } & Baseline & $3.84(3.29)$ & $3.75(1.66)$ & $3.27(2.38)$ & 0.343 & 0.176 \\
\hline & 10th wk & $3.99(3.00)$ & $2.97(1.27)$ & $3.33(2.25)$ & 0.350 & 0.06 \\
\hline & Changes & 0.15 & -0.78 & 0.06 & 0.001 & 0.001 \\
\hline & $P^{* * *}$ & 0.06 & 0.006 & .526 & & \\
\hline \multirow[t]{4}{*}{ HOMA-IR } & Baseline & 3.01 (1.92) & $2.71(1.58)$ & $2.30(0.86)$ & 0.351 & 0.345 \\
\hline & 10th wk & $3.46(2.35)$ & $1.90(1.33)$ & $1.73(0.95)$ & 0.001 & 0.001 \\
\hline & Changes & 0.45 & -0.81 & -0.57 & $<0.001$ & 0.002 \\
\hline & $P^{* * *}$ & 0.201 & $<0.001$ & 0.004 & & \\
\hline \multirow[t]{4}{*}{ SHBG (nmol/L) } & Baseline & $50.96(34.84)$ & $32.47(14.11)$ & 44.06 (35.69) & 0.112 & 0.030 \\
\hline & 10th wk & $42.50(22.49)$ & 38.07 (22.9) & $45.62(37.57)$ & 0.703 & 0.503 \\
\hline & Changes & -8.46 & 5.6 & 1.56 & 0.410 & 0.139 \\
\hline & $P^{* * *}$ & 0.124 & 0.161 & 0.836 & & \\
\hline
\end{tabular}

a HDL high-density lipoproteins, LDL low-density lipoproteins, TG triglyceride, TC Total cholesterol, HOMA-IR Homeostatic Model Assessment of Insulin Resistance, SHBG Sex hormone-binding globulin. ${ }^{b}$ Data are presented as mean (SD) or geometric mean (SD). ${ }^{*}$ Calculated using one-way ANOVA. ${ }^{* *}$ Calculated using ANCOVA, adjusted for the effect of energy, carbohydrate, protein, weight and baselines. ${ }^{* * *}$ Calculated using paired sample t-test 
Table 5 Comparisons of the Changes of fatty Liver Status from Baseline to the End of the Intervention in the three Groups

\begin{tabular}{|c|c|c|c|c|c|c|c|c|c|c|}
\hline \multirow{2}{*}{$\begin{array}{l}\text { Grade } \\
\text { of } \\
\text { NAFLD } \\
\%\end{array}$} & \multicolumn{3}{|c|}{ sunflower oil group( $(n=24)$} & \multicolumn{3}{|c|}{ canola oil group $(n=24)$} & \multicolumn{3}{|c|}{ olive oil group( $(n=24)$} & \multirow{2}{*}{$\begin{array}{l}P \text { - } \\
\text { value }\end{array}$} \\
\hline & before & after & $P$-value & before & after & $P$-value & before & after & $P$-value & \\
\hline Grade 0 & $11(45.8)$ & $11(45.8)$ & 1 & $6(25.0)$ & $16(66.7)$ & $<0.001$ & $10(41.7)$ & $17(70.8)$ & 0.005 & 0.404 \\
\hline Grade 1 & $9(37.5)$ & $9(37.5)$ & & $13(54.2)$ & $6(25.0)$ & & $12(50.0)$ & $6(25.0)$ & & \\
\hline Grade 2 & $4(16.7)$ & $4(16.7)$ & & $5(20.8)$ & $2(8.3)$ & & $2(8.3)$ & $1 \mathrm{~s}(4.2)$ & & \\
\hline
\end{tabular}

NAFLD Non-Alcoholic Fatty Liver Disease

$P$-values are resulted from ANOVA or Chi-Square or kruskal-wallis test

\section{Discussion}

The present study investigated the effects of canola, olive, and sunflower oils on lipid profile and NAFLD severity among women with PCOS for 70 days. Findings showed that canola oil can exert beneficial effects on some lipid profile parameters and fatty liver severity. Moreover, olive oil consumption resulted in significant improvement in fatty liver severity, while it had no effects on the lipid profile.

Canola and olive oils compared to sunflower oil, caused a marked decrease in HOMA-IR. However, SHBG levels had no significant changes in all three groups postintervention. Our results were similar to the findings of some studies which reported improved insulin sensitivity by consuming omega-3 fatty acids. In 2012, Rafraf et al. conducted a study on 61 overweight or obese women with PCOS and reported significant reductions in FSG, FSI, and HOMA-IR but no significant changes in weight, BMI after taking omega-3 fatty acids [62]. Omega-3 fatty acids could exert their positive effect on insulin sensitivity by altering glucose transporters (GLUT1 and GLUT4) levels in muscle and adipose tissue. Moreover, Nigam et al. showed improved insulin sensitivity in NAFLD subjects using high-MUFA oil compared to a control oil group. The proposed mechanism can be the improvement of glucagonlike peptide-1 responses in insulin-resistant individuals and up-regulation of glucose transporter- 2 expression in the liver [32]. Conversely, other studies presented no significant differences in BMI, FSG, FSI, HOMA-IR, SHBG after receiving $4 \mathrm{~g}$ of omega-3 fatty acids per day $[63,64]$.

Previous studies reported that the changes in dietary fatty acid composition, especially replacement of SFA with PUFA and MUFA can improve blood lipid levels even in those participants with low initial concentrations [65]. Participants in the canola oil group demonstrated a significant decrease in serum TG and Non-HDL-c concentrations and TC/HDL-c, LDL-c/HDL-c, and TG/ HDL-c ratios. Also, a marginally significant effect on TC and LDL-c concentrations was observed in canola oil. Ghobadi et al., in their meta-analysis study, showed that canola oil decreased LDL-c and TC compared to sunflower oil $[66,67]$. Also, Sarkkinen et al. performed a 6month dietary intervention trial in hypercholesterolemic patients and found that LDL-c levels in the canola oil group were lowered by $3.7 \%$ from the baseline levels [68]. Canola oil's effect on TC and LDL-c may depend on the types of fatty acids replaced by oil, study duration, and baseline levels of TC and LDL-c [69].

Looking at the previous findings, the effects of various oils on blood lipids is a controversial area [70, 71]. Although olive and canola oils contain high amounts of MUFA [72], canola oil has a higher content of PUFAs, especially ALA, and lower SFA [28]. The exact mechanisms of Canola oil on serum lipids are not well known; however, it could be related to its fatty acid composition [73]. Furthermore, in this trial, canola oil compared to olive oil caused more reduction in HOMA-IR (0.81 vs. 0.57; Table 4). Higher ALA intake can elevate insulin secretion, improve insulin sensitivity, and lipoprotein lipase activity, leading to serum TG reduction [74]. After consuming canola oil, this can be the reason for the significant decrease in TG concentrations. Olive oil consumption led to a non-significant increase in TG levels. Moreover, omega-3 FA content of canola oil can downregulate VLDL-C and apolipoprotein-B100 synthesis which can, in turn, lower serum TG concentrations [12]. Previous studies reported that a dietary pattern with a higher PUFA amount could decrease serum LDL-c and TC but not TG and HDL-c $[75,76]$. Canola oil supplementation caused a marginally significant reduction in LDL-c and TC concentrations (Table 4). Salar et al. in a clinical trial showed that canola oil at the dose of $30 \mathrm{~g} /$ day decreased serum LDL-c more than sunflower oil, a poor source of ALA [57]. Furthermore, in Sacks et al.'s trial, they found a significant decrement in serum LDL-c and TC/HDL-c ratio following the replacement of SFA by canola oil [77]. In addition, canola oil consumption led to a significant reduction in TC/HDL-c, LDL-c /HDL-c, and TG/HDL-c ratios, known as the main predictors of CVD [78]. Higher intake of canola oil can reduce the risk of coronary heart disease and all-cause and cardiovascular mortality attributed to its PUFA content [73].

This intervention was unable to find any significant reduction in lipid profile in response to olive oil consumption. The results of some previous studies are in contradiction with available findings. Venturini et al., in 
their clinical trial, found that extra virgin $10 \mathrm{~mL} /$ day olive oil combined with fish oil ( $3 \mathrm{~g} /$ day) lowered the serum levels of TC and TC/HDL-c and LDL-c/HDL-c ratios [33]. Extra virgin olive oil in a dosage of $4 \mathrm{~g} /$ day in mildly hypocholesterolemic participants caused favorable changes in plasma lipid profile [79]. The mechanisms in which olive oil can exert its beneficial antioxidative effect can be clarified by polyphenol activity or through the cumulative protective effect of its polyphenols and MUFA content [78]. In a recent meta-analysis, researchers reported that olive oil significantly reduced serum levels of TC, LDL-c, and TG but to less extent than other vegetable oils, specifically in subgroup analysis for refined olive oil [80]. In this research, using refined olive oil could cause a lack of beneficial effects of olive oil on blood lipids. Also, different FA compositions of olive oil compared to canola oil could be a reason for the impaired beneficial effect on lipid profile (Table 1). Ghobadi et al. demonstrated that the reduction of TC by olive oil was significantly lower than that of omega-3 rich oils [80]. On the other hand, the ratio of n-6 to $n-3$ fatty acids is known to influence inflammatory state in PCOS women [81]. Several studies illustrated that a higher intake of n-6 PUFA increases CVD risk, which is independently associated with elevated serum TC and TG levels [82].

Olive and canola oils could decrease fatty liver severity; however, they had no significant differences. Nigam et al. in an interventional study including 93 males with NAFLD, showed that consuming olive and canola oils at the dose of $20 \mathrm{~g} /$ day resulted in a significant decline in fatty liver grade and other NAFLD risk factors [32]. Kruse et al. compared the efficacy of canola and olive oils on hepatic steatosis in obese men. In their study, 27 obese men consumed $50 \mathrm{~g} /$ day of either canola or olive oils for 8 weeks. The results showed that canola oil compared to olive oil caused a greater reduction in hepatic steatosis [81].

Dietary ingredients, especially the type and amount of fats, are important in liver fat deposition, which is responsible for $15 \%$ of liver fat content [31]. Reduction in n-3 PUFA levels and augment in n-6 PUFAs exacerbate hepatic steatosis by inhibiting transcription factor activity of PPAR- $\alpha$ which promotes a pro-lipogenic and proinflammatory state. PPAR- $\alpha$ is presented in tissues with a high FA oxidation activity, such as the liver [83-85]. The faster oxidation of MUFAs can clarify the positive effects of olive oil on hepatic fat content than SFA in the postprandial phase [86]. For instance, consumption of diets rich in MUFA (28\% of total calories) for 8 weeks by patients with type 2 diabetes reduced liver fat by $30 \%$. This decline was associated with elevated postprandial $\beta$ oxidation of fatty acids [87]. Errazuriz et al. in their RCT indicated that high MUFA intake (28\% of energy, half as olive oil) in prediabetes patients for 12 weeks lowered hepatic fat and improved insulin sensitivity. Moreover, a high-MUFA diet boosts lipoprotein lipase activity more than a diet rich in SFA resulting in enhanced clearance of circulating triglyceride-rich lipoproteins [86]. Furthermore, a higher amount of MUFA and ALA in canola oil can exert beneficial effects against fatty liver by improving insulin sensitivity, glucagon-like peptide-1 responses, and up-regulation of glucose transporter-2 expression in the liver of insulin-resistant participants [88]. In addition, a higher intake of ALA and a lower ratio of n6/ n3 PUFA can enhance lipid oxidation, inhibit hepatic triacylglycerol synthesis by PPAR- $\alpha$ activation mechanism. This transcription factor precisely plays a role in lipid metabolism by favoring the expression of numerous genes involved in FA oxidation, which inhibit de novo lipogenesis [89-91]. Therefore, PPAR- $\alpha$ activation is likely to improve NAFLD [92].

In this study, only women were included. There is a sex difference in the conversion of ALA to EPA and DHA, which is higher in women than that of men. The females have higher erythrocyte phospholipid EPA and higher plasma DHA content. Previous studies showed an inverse relationship between the menopausal status of women and the age of female participants with the change in plasma EPA content after olive oil supplementation [24, 25]. A part of this study inconsistency compared to other studies could be attributed to such differences.

SHBG expression regulation by oleic acid can be modulated or even attenuated by estradiol. Moreover, olive oil intake is associated with elevated levels of SHBG and PPAR- downregulation induced by oleoyl-CoA that seems to be an underlying mechanism in such regulation. Interestingly, olive oil is one of the main components of the Mediterranean diet and SHBG levels were associated with a lower risk of cardiovascular disease [93]. To add more, Oner and Muderris carried out a study on 45 non-obese women with PCOS. They received $1500 \mathrm{mg}$ of omega-3 fatty acids daily for 6 months. Findings showed a significant decrease in BMI, FSI, HOMA-IR and a significant increase in SHBG and TNF- $\alpha$ due to supplementation with omega- 3 fatty acids [94]. The limitations of the present study can be the cause of insignificant effect at the SHBG level.

No significant results were found for sunflower oil effect on lipid profile and fatty liver severity. Sunflower oil is a rich source of omega- 6 fatty acids. Previous studies indicated that high intake of foods rich in omega- 6 fatty acids could exacerbate inflammation and liver damage [84, 95, 96]. It is worthy to note that due to the availability and cost of sunflower oil compared to olive or canola oil, most people, especially middle-income or low-income families tend to use this type of oil in their food preparation. 


\section{Study strength and limitation}

The study design was a double-blind randomized clinical trial to assess three types of conventional oils from different sources while comparing two high MUFA oils. The main limitation of this study was the method of fatty liver evaluation. Ultrasound is not very accurate to detect mild cases of the fatty liver compared to the more recent Fibroscan method. The other limitation was the study duration. It was not possible to measure the gene which promotes the SHBG and also to measure the ALA, EPA, and DHA content of erythrocyte membranes as a good indicator of the participants' adherence.

\section{Conclusion}

Canola oil, as a good source of MUFA and ALA, showed beneficial effects on lipid profile compared to olive, and sunflower oils in women with PCOS. The role of ALA and a lower ratio of $n 6 / n 3$ PUFA should be considered in addition to the positive effect of MUFA in the canola oil. Also, the substitution of canola or olive oils for sunflower oil could attenuate fatty liver status in women with PCOS. Because the effects may depend on the dose of oils consumed, more studies are warranted to determine the proper amounts to achieve the best results.

\section{Abbreviations \\ PCOS: Polycystic Ovarian Syndrome; CVD: Cardiovascular Diseases; T2D: Type 2 Diabetes; SFAs: Saturated Fatty Acids; MUFAs: Mono-Unsaturated Fatty Acids; PUFAs: Polyunsaturated Fatty Acids; EPA: Eicosapentaenoic Acid; DHA: Docosahexaenoic Acid; ALA: a-Linolenic Acid; IR: Insulin Resistance; TC: Total Cholesterol; HDL: High-Density Lipoprotein; LDL: Low-Density Lipoprotein; TG: Triglyceride; NAFLD: Non-Alcoholic Fatty Liver Disease; BMI: Body Mass Index; OCP: Oral Contraceptive Pill; PPAR-a: Peroxisome proliferator-activated receptor alpha; SREBP-1c: Sterol regulatory element- binding protein 1; HOMA-IR: Homeostatic Model Assessment of Insulin Resistance; SHBG: Sex hormone-binding globulin; FSG: Fasting Serum Glucose; FSI: Fasting Serum Insulin; TNF-a: Tumor Necrosis Factor Alpha; GLUT: Glucose Transporter}

\section{Acknowledgements}

Not applicable.

\section{Authors' contributions}

All authors read and approved final manuscript.

\section{Funding}

Not applicable.

\section{Availability of data and materials}

Datasets used and/or analyzed during current study are available from corresponding author on reasonable request.

\section{Ethics approval and consent to participate}

This study was conformed to the declaration of Helsinki and Good Clinical Practice Guidelines. The protocol of present study was reviewed and approved by Medical Ethics Committee at Isfahan University of Medical Sciences, Iran (ethics registration number: IR.MUI.RESEARCH.REC.1397.315) which registered at Iranian Registry of Clinical Trials (approval code: 38684).

\section{Consent for publication}

Not applicable.

\section{Competing interests}

The authors declare that they have no competing interests.

\section{Author details}

${ }^{1}$ Nutrition and Food Sciences, Isfahan University of Medical Sciences, Isfahan, Iran. ${ }^{2}$ Metabolic Liver Disease Research Center, Isfahan University of Medical Sciences, Isfahan, Iran. ${ }^{3}$ Department of Biostatistics and Epidemiology, School of Health, Isfahan University of Medical Sciences, Isfahan, Iran. ${ }^{4}$ Department of Obstetrics and Gynecology, Medical School, Isfahan University of Medical Sciences, Isfahan, Iran. ${ }^{5}$ Food Security Research Center, Isfahan University of Medical Sciences, Isfahan, Iran.

Received: 24 September 2020 Accepted: 14 January 2021

Published online: 29 January 2021

\section{References}

1. Escobar-Morreale HF. Polycystic ovary syndrome: definition, aetiology, diagnosis and treatment. Nat Rev Endocrinol. 2018;14(5):270.

2. Farooq R. Short review on polycystic ovarian syndrome. J Med. 2018;19(1): 49-53.

3. Ding T, Hardiman PJ, Petersen I, Wang F-F, Qu F, Baio G. The prevalence of polycystic ovary syndrome in reproductive-aged women of different ethnicity: a systematic review and meta-analysis. Oncotarget. 2017;8(56): 96351.

4. Hahn S, Janssen OE, Tan S, Pleger K, Mann K, Schedlowski M, et al. Clinical and psychological correlates of quality-of-life in polycystic ovary syndrome. Eur J Endocrinol. 2005;153(6):853-60.

5. Azziz R. Androgen excess is the key element in polycystic ovary syndrome. Fertil Steril. 2003;80(2):252.

6. Macut D, Bjekić-Macut J, Savić-Radojević A. Dyslipidemia and oxidative stress in PCOS. Front Horm Res. 2013;40:51-63.

7. Dokras A. Cardiovascular disease risk in women with PCOS. Steroids. 2013; 78(8):773-6.

8. Orio F, Palomba S, Colao A. Cardiovascular risk in women with polycystic ovary syndrome. Fertil Steril. 2006;86:S20-S1.

9. Hillman JK, Johnson LN, Limaye M, Feldman RA, Sammel M, Dokras A. Black women with polycystic ovary syndrome (PCOS) have increased risk for metabolic syndrome and cardiovascular disease compared with white women with PCOS. Fertil Steril. 2014;101(2):530-5.

10. Wild RA, Painter P, COULSON PB, CARRUTH KB, Ranney G. Lipoprotein lipid concentrations and cardiovascular risk in women with polycystic ovary syndrome. J Clin Endocrinol Metab. 1985;61(5):946-51.

11. Rocha MP, Marcondes JA, Barcellos CR, Hayashida SA, Curi DD, da Fonseca $\hat{A} M$, et al. Dyslipidemia in women with polycystic ovary syndrome: incidence, pattern and predictors. Gynecol Endocrinol. 2011;27(10):814-9.

12. Wild RA. Dyslipidemia in PCOS. Steroids. 2012;77(4):295-9.

13. Hernandez-Rodas MC, Valenzuela R, Videla LA. Relevant aspects of nutritional and dietary interventions in non-alcoholic fatty liver disease. Int J Mol Sci. 2015;16(10):25168-98.

14. Shishehgar F, Tehrani FR, Mirmiran P, Hajian S, Baghestani AR, Moslehi N. Comparison of dietary intake between polycystic ovary syndrome women and controls. Global J Health Sci. 2016;8(9):302.

15. Altieri P, Cavazza C, Pasqui F, Morselli AM, Gambineri A, Pasquali R. Dietary habits and their relationship with hormones and metabolism in overweight and obese women with polycystic ovary syndrome. Clin Endocrinol. 2013; 78(1):52-9.

16. Panagiotakos DB, Georgousopoulou EN, Pitsavos C, Chrysohoou C, Skoumas I, Pitaraki E, et al. Exploring the path of Mediterranean diet on 10-year incidence of cardiovascular disease: the ATTICA study (2002-2012). Nutr Metab Cardiovasc Dis. 2015;25(3):327-35.

17. Mozaffarian D, Micha R, Wallace S. Effects on coronary heart disease of increasing polyunsaturated fat in place of saturated fat: a systematic review and meta-analysis of randomized controlled trials. PLoS Med. 2010;7(3): e1000252.

18. Harris WS. N-3 fatty acids and serum lipoproteins: human studies. Am J Clin Nutr. 1997;65(5):1645S-54S.

19. Sanders T, Oakley F, Miller G, Mitropoulos K, Crook D, Oliver M. Influence of $\mathrm{n}-6$ versus $\mathrm{n}-3$ polyunsaturated fatty acids in diets low in saturated fatty acids on plasma lipoproteins and hemostatic factors. Arterioscler Thromb Vasc Biol. 1997:17(12):3449-60.

20. Bowen KJ, Harris WS, Kris-Etherton PM. Omega-3 fatty acids and cardiovascular disease: are there benefits? Curr Treat Options Cardiovas Med. 2016;18(11):69. 
21. Krebs J, Browning L, McLean N, Rothwell J, Mishra G, Moore C, et al. Additive benefits of long-chain n-3 polyunsaturated fatty acids and weightloss in the management of cardiovascular disease risk in overweight hyperinsulinaemic women. Int J Obes. 2006;30(10):1535-44.

22. Lombardo YB, Chicco AG. Effects of dietary polyunsaturated n-3 fatty acids on dyslipidemia and insulin resistance in rodents and humans. A review. J Nutr Biochem. 2006;17(1):1-13.

23. Burdge GC, Jones AE, Wootton SA. Eicosapentaenoic and docosapentaenoic acids are the principal products of a-linolenic acid metabolism in young men. Br J Nutr. 2002:88(4):355-63.

24. Burdge GC, Wootton SA. Conversion of a-linolenic acid to eicosapentaenoic, docosapentaenoic and docosahexaenoic acids in young women. $\mathrm{Br} J$ Nutr. 2002;88(4):411-20.

25. Lohner S, Fekete K, Marosvolgyi T, Decsi T. Gender differences in the longchain polyunsaturated fatty acid status: systematic review of 51 publications. Ann Nutr Metab. 2013;62(2):98-112.

26. Gibson RA, Muhlhausler B, Makrides M. Conversion of linoleic acid and alpha-linolenic acid to long-chain polyunsaturated fatty acids (LCPUFAs), with a focus on pregnancy, lactation and the first 2 years of life. Matern Child Nutr. 2011;7:17-26.

27. Leikin Al, Brenner RR. Fatty acid desaturase activities are modulated by phytosterol incorporation in microsomes. Biochim Biophys Acta. 1989; 1005(2):187-91.

28. Dittrich M, Jahreis $G$, Bothor K, Drechsel C, Kiehntopf M, Blüher M, et al. Benefits of foods supplemented with vegetable oils rich in a-linolenic, stearidonic or docosahexaenoic acid in hypertriglyceridemic subjects: a double-blind, randomized, controlled trail. Eur J Nutr. 2015;54(6):881-93.

29. Bonaccio M, Pounis G, Cerletti C, Donati MB, lacoviello L, de Gaetano G. Mediterranean diet, dietary polyphenols and low grade inflammation: results from the MOLI-SANI study. Br J Clin Pharmacol. 2017:83(1):107-13.

30. Childs CE, Kew S, Finnegan YE, Minihane AM, Leigh-Firbank EC, Williams CM, et al. Increased dietary alpha-linolenic acid has sex-specific effects upon eicosapentaenoic acid status in humans: re-examination of data from a randomised, placebo-controlled, parallel study. Nutr J. 2014;13(1):113.

31. Jenkins DJ, Kendall CW, Vuksan V, Faulkner D, Augustin LS, Mitchell S, et al. Effect of lowering the glycemic load with canola oil on glycemic control and cardiovascular risk factors: a randomized controlled trial. Diabetes Care. 2014;37(7):1806-14.

32. Nigam P, Bhatt S, Misra A, Chadha DS, Vaidya M, Dasgupta J, et al. Effect of a 6-month intervention with cooking oils containing a high concentration of monounsaturated fatty acids (olive and canola oils) compared with control oil in male Asian Indians with nonalcoholic fatty liver disease. Diabetes Technol Ther. 2014;16(4):255-61.

33. Venturini $D$, Simão ANC, Urbano MR, Dichi I. Effects of extra virgin olive oil and fish oil on lipid profile and oxidative stress in patients with metabolic syndrome. Nutrition. 2015;31(6):834-40.

34. Aparicio-Soto M, Sánchez-Hidalgo M, Rosillo MÁ, Castejón ML, Alarcón-dela-Lastra C. Extra virgin olive oil: a key functional food for prevention of immune-inflammatory diseases. Food Funct. 2016:7(11):4492-505.

35. Yu L, Yuan M, Wang L. The effect of omega-3 unsaturated fatty acids on non-alcoholic fatty liver disease: A systematic review and meta-analysis of RCTs. Pak J Med Sci. 2017;33(4):1022-8.

36. Ascaso JF, Pardo S, Real JT, Lorente RI, Priego A, Carmena R. Diagnosing insulin resistance by simple quantitative methods in subjects with normal glucose metabolism. Diabetes Care. 2003;26(12):3320-5.

37. Wallace TM, Levy JC, Matthews DR. Use and abuse of HOMA modeling. Diabetes Care. 2004;27(6):1487-95.

38. Lunger $F$, Wildt $L$, Seeber B. Accurate screening for insulin resistance in PCOS women using fasting insulin concentrations. Gynecol Endocrinol. 2013;29(6):541-4.

39. Dunaif A, Segal KR, Futterweit W, Dobrjansky A. Profound peripheral insulin resistance, independent of obesity, in polycystic ovary syndrome. Diabetes. 1989;38(9):1165-74.

40. Teede HJ, Hutchison SK, Zoungas S. The management of insulin resistance in polycystic ovary syndrome. Trends Endocrinol Metab. 2007;18(7):273-9.

41. Pugeat M, Nader N, Hogeveen K, Raverot G, Déchaud H, Grenot C. Sex hormone-binding globulin gene expression in the liver: drugs and the metabolic syndrome. Mol Cell Endocrinol. 2010;316(1):53-9.

42. GLASS AR, SWERDLOFF RS, BRAY GA, DAHMS WT, ATKINSON RL. Low serum testosterone and sex-hormone-binding-globulin in massively obese men. J Clin Endocrinol Metabo. 1977:45(6):1211-9.
43. Stefan N, Schick F, Häring H-U. Sex hormone-binding globulin and risk of type 2 diabetes. N Engl J Med. 2009;361(27):2675.

44. Peter A, Kantartzis K, Machann J, Schick F, Staiger H, Machicao F, et al. Relationships of circulating sex hormone-binding globulin with metabolic traits in humans. Diabetes. 2010;59(12):3167-73.

45. Laaksonen DE, Niskanen L, Punnonen K, Nyyssönen K, Tuomainen T-P, Valkonen V-P, et al. Testosterone and sex hormone-binding globulin predict the metabolic syndrome and diabetes in middle-aged men. Diabetes Care. 2004;27(5):1036-41.

46. Kalme T, Seppälä M, Qiao Q, Koistinen R, Nissinen A, Harrela M, et al. Sex hormone-binding globulin and insulin-like growth factor-binding protein-1 as indicators of metabolic syndrome, cardiovascular risk, and mortality in elderly men. J Clin Endocrinol Metab. 2005;90(3):1550-6.

47. Ding EL, Song Y, Manson JE, Hunter DJ, Lee CC, Rifai N, et al. Sex hormonebinding globulin and risk of type 2 diabetes in women and men. N Engl J Med. 2009;361(12):1152-63.

48. Lindstedt G, Lundberg P-A, Lapidus L, Lundgren H, Bengtsson C, Björntorp $P$. Low sex-hormone-binding globulin concentration as independent risk factor for development of NIDDM: 12-yr follow-up of population study of women in Gothenburg. Diabetes. 1991;40(1):123-8.

49. Sutton-Tyrrell K, Wildman RP, Matthews KA, Chae C, Lasley BL, Brockwell S, et al. Sex hormone-binding globulin and the free androgen index are related to cardiovascular risk factors in multiethnic premenopausal and perimenopausal women enrolled in the study of women across the nation (SWAN). Circulation. 2005;111(10):1242-9.

50. Lapidus L, Lindstedt G, Lundberg P, Bengtsson C, Gredmark T. Concentrations of sex-hormone binding globulin and corticosteroid binding globulin in serum in relation to cardiovascular risk factors and to 12-year incidence of cardiovascular disease and overall mortality in postmenopausal women. Clin Chem. 1986:32(1):146-52.

51. Haffner SM, Katz MS, Stern MP, Dunn JF. Association of decreased sex hormone binding globulin and cardiovascular risk factors. Arteriosclerosis. 1989;9(1):136-43.

52. Botwood N, Hamilton-Fairley D, Kiddy D, Robinson S, Franks S. Sex hormone-binding globulin and female reproductive function. J Steroid Biochem Mol Biol. 1995;53(1-6):529-31.

53. Rosner W, Hryb DJ, Khan MS, Nakhla AM, Romas NA. Sex hormone-binding globulin: anatomy and physiology of a new regulatory system. J Steroid Biochem Mol Biol. 1991;40(4-6):813-20.

54. Pugeat M, Crave JC, Tourniaire J, Forest MG. Clinical utility of sex hormonebinding globulin measurement. Horm Res. 1996;45(3-5):148-55.

55. Teede H, Deeks A, Moran L. Polycystic ovary syndrome: a complex condition with psychological, reproductive and metabolic manifestations that impacts on health across the lifespan. BMC Med. 2010;8(1):41.

56. Wang R, Mol BWJ. The Rotterdam criteria for polycystic ovary syndrome: evidence-based criteria? Hum Reprod. 2017;32(2):261-4.

57. Salar A, Faghih S, Pishdad GR. Rice bran oil and canola oil improve blood lipids compared to sunflower oil in women with type 2 diabetes: A randomized, single-blind, controlled trial. J Clin Lipidol. 2016;10(2):299-305.

58. Vasheghani-Farahani A, Tahmasbi M, Asheri H, Ashraf H, Nedjat S, Kordi R. The Persian, last 7-day, long form of the international physical activity questionnaire: translation and validation study. Asian J Sports Med. 2011; 2(2):106.

59. Guarrasi V, Mangione M, Sanfratello V, Martorana V, Bulone D. Quantification of underivatized fatty acids from vegetable oils by HPLC with UV detection. J Chromatogr Sci. 2010;48(8):663-8.

60. Matthews D, Hosker J, Rudenski A, Naylor B, Treacher D, Turner R. Homeostasis model assessment: insulin resistance and $\beta$-cell function from fasting plasma glucose and insulin concentrations in man. Diabetologia. 1985;28(7):412-9.

61. Katz A, Nambi SS, Mather K, Baron AD, Follmann DA, Sullivan G, et al. Quantitative insulin sensitivity check index: a simple, accurate method for assessing insulin sensitivity in humans. J Clin Endocrinol Metab. 2000;85(7):2402-10.

62. Rafraf M, Mohammadi E, Asghari-Jafarabadi M, Farzadi L. Omega-3 fatty acids improve glucose metabolism without effects on obesity values and serum visfatin levels in women with polycystic ovary syndrome. J Am Coll Nutr. 2012;31(5):361-8

63. Cussons AJ, Watts GF, Mori TA, Stuckey BG. Omega-3 fatty acid supplementation decreases liver fat content in polycystic ovary syndrome: a randomized controlled trial employing proton magnetic resonance spectroscopy. J Clin Endocrinol Metab. 2009;94(10):3842-8. 
64. Phelan N, O'Connor A, Kyaw Tun T, Correia N, Boran G, Roche HM, et al. Hormonal and metabolic effects of polyunsaturated fatty acids in young women with polycystic ovary syndrome: results from a cross-sectional analysis and a randomized, placebo-controlled, crossover trial. Am J Clin Nutr. 2011;93(3):652-62.

65. Liu J, Sempos C, Donahue RP, Dorn J, Trevisan M, Grundy SM. Joint distribution of non-HDL and LDL cholesterol and coronary heart disease risk prediction among individuals with and without diabetes. Diabetes Care. 2005;28(8):1916-21.

66. Ghobadi S, Hassanzadeh-Rostami Z, Mohammadian F, Zare M, Faghih S. Effects of canola oil consumption on lipid profile: A systematic review and meta-analysis of randomized controlled clinical trials. J Am Coll Nutr. 2019; 38(2):185-96.

67. Tholstrup T, Marckmann P, Jespersen J, Sandström B. Fat high in stearic acid favorably affects blood lipids and factor VII coagulant activity in comparison with fats high in palmitic acid or high in myristic and lauric acids. Am J Clin Nutr. 1994:59(2):371-7.

68. Sarkkinen ES, Uusitupa MI, Gylling H, Miettinen TA. Fat-modified diets influence serum concentrations of cholesterol precursors and plant sterols in hypercholesterolemic subjects. Metabolism. 1998;47(6):744-50.

69. Lin L, Allemekinders H, Dansby A, Campbell L, Durance-Tod S, Berger A, et al. Evidence of health benefits of canola oil. Nutr Rev. 2013;71(6):370-85.

70. Rodríguez-Villar C, Manzanares JM, Casals E, Pérez-Heras A, Zambón D, Gomis R, et al. High-monounsaturated fat, olive oil-rich diet has effects similar to a high-carbohydrate diet on fasting and postprandial state and metabolic profiles of patients with type 2 diabetes. Metabolism. 2000;49(12): 1511-7.

71. Huth PJ, Fulgoni VL 3rd, Larson BT. A systematic review of high-oleic vegetable oil substitutions for other fats and oils on cardiovascular disease risk factors: implications for novel high-oleic soybean oils. Adv Nutr. 2015; 6(6):674-93.

72. Tarrago-Trani MT, Phillips KM, Lemar LE, Holden JM. New and existing oils and fats used in products with reduced trans-fatty acid content. J Am Diet Assoc. 2006;106(6):867-80.

73. Hoffman R, Gerber M. Can rapeseed oil replace olive oil as part of a Mediterranean-style diet? Br J Nutr. 2014;112(11):1882-95.

74. Muramatsu T, Yatsuya H, Toyoshima H, Sasaki S, Li Y, Otsuka R, et al. Higher dietary intake of alpha-linolenic acid is associated with lower insulin resistance in middle-aged Japanese. Prev Med. 2010;50(5-6):272-6.

75. Mensink RP, Zock PL, Kester AD, Katan MB. Effects of dietary fatty acids and carbohydrates on the ratio of serum total to HDL cholesterol and on serum lipids and apolipoproteins: a meta-analysis of 60 controlled trials. Am J Clin Nutr. 2003;77(5):1146-55

76. Ramprasath VR, Jones PJ, Buckley DD, Woollett LA, Heubi JE. Decreased plasma cholesterol concentrations after PUFA-rich diets are not due to reduced cholesterol absorption/synthesis. Lipids. 2012;47(11):1063-71.

77. Sacks FM, Katan M. Randomized clinical trials on the effects of dietary fat and carbohydrate on plasma lipoproteins and cardiovascular disease. Am J Med. 2002;113(9):13-24.

78. Fitó M, Covas MI, Lamuela-Raventós RM, Vila J, Torrents J, de la Torre C, et al. Protective effect of olive oil and its phenolic compounds against low density lipoprotein oxidation. Lipids. 2000;35(6):633-8.

79. Violante B, Gerbaudo L, Borretta G, Tassone F. Effects of extra virgin olive oil supplementation at two different low doses on lipid profile in mild hypercholesterolemic subjects: a randomised clinical trial. J Endocrinol Investig. 2009;32(10):794-6.

80. Ghobadi S, Hassanzadeh-Rostami Z, Mohammadian F, Nikfetrat A. Ghasemifard n, Raeisi Dehkordi H, et al. comparison of blood lipid-lowering effects of olive oil and other plant oils: A systematic review and metaanalysis of 27 randomized placebo-controlled clinical trials. Crit Rev Food Sci Nutr. 2019;59(13):2110-24.

81. Kruse M, Kemper M, Gancheva S, Osterhoff M, Dannenberger D, Markgraf D, et al. Dietary rapeseed oil supplementation reduces hepatic Steatosis in obese men-A randomized controlled trial. Mol Nutr Food Res. 2020;64(21): e2000419.

82. Szostak-Wegierek D, Kłosiewicz-Latoszek L, Szostak WB, Cybulska B. The role of dietary fats for preventing cardiovascular disease. Rocz Panstw Zakl Hig. 2013;64(4):263-9.

83. Donnelly KL, Smith Cl, Schwarzenberg SJ, Jessurun J, Boldt MD, Parks EJ. Sources of fatty acids stored in liver and secreted via lipoproteins in patients with nonalcoholic fatty liver disease. J Clin Invest. 2005;115(5):1343-51.
84. Valenzuela $R$, Videla LA. The importance of the long-chain polyunsaturated fatty acid $n-6 / n-3$ ratio in development of non-alcoholic fatty liver associated with obesity. Food Funct. 2011;2(11):644-8.

85. Valenzuela R, Videla LA. Impact of the co-administration of N-3 fatty acids and olive oil components in preclinical nonalcoholic fatty liver disease models: a mechanistic view. Nutrients. 2020;12(2):499.

86. Rivellese AA, Giacco R, Annuzzi G, De Natale C, Patti L, Di Marino L, et al. Effects of monounsaturated vs. saturated fat on postprandial lipemia and adipose tissue lipases in type 2 diabetes. Clin Nutr. 2008;27(1):133-41.

87. Bozzetto L, Costabile G, Luongo D, Naviglio D, Cicala V, Piantadosi C, et al. Reduction in liver fat by dietary MUFA in type 2 diabetes is helped by enhanced hepatic fat oxidation. Diabetologia. 2016;59(12):2697-701.

88. Nigam P, Bhatt S, Vaidya M, Misra A, Pasha MQ. Effect of dietary intervention with canola oil on non-alcoholic fatty liver disease subjects among north Indians_A controlled intervention study. J Clin Exp Hepatol. 2011;1(1):30.

89. Wong S, Nestel P, Trimble R, Stoker G, Illman R, Topping D. The adaptive effects of dietary fish and safflower oil on lipid and lipoprotein metabolism in perfused rat liver. Biochim Biophys Acta. 1984;792(2):103-9.

90. Echeverría F, Ortiz M, Valenzuela R, Videla LA. Long-chain polyunsaturated fatty acids regulation of PPARs, signaling: relationship to tissue development and aging. Prostaglandins Leukot Essent Fat Acids. 2016;114: 28-34.

91. Stienstra R, Duval C, Müller M, Kersten S. PPARs, obesity, and inflammation. PPAR Res. 2007:2007:95974.

92. Valenzuela R, Ortiz M, Hernández-Rodas MC, Echeverría F, Videla LA. Targeting n-3 Polyunsaturated Fatty Acids in Non-Alcoholic Fatty Liver Disease. Curr Med Chem. 2020;27(31):5250-72.

93. Sáez-López C, Soriguer F, Hernandez C, Rojo-Martinez G, Rubio-Martín E, Simó $\mathrm{R}$, et al. Oleic acid increases hepatic sex hormone binding globulin production in men. Mol Nutr Food Res. 2014;58(4):760-7.

94. Oner G, Muderris I. Efficacy of omega-3 in the treatment of polycystic ovary syndrome. J Obstet Gynaecol. 2013;33(3):289-91.

95. Araya J, Rodrigo R, Videla L, Thielemann L, Orellana M, Pettinelli P, et al. Increase in long-chain polyunsaturated nuclear receptor peroxisome proliferator-activated receptor alpha fatty acid n-6/n-3 ratio in relation to hepatic steatosis in patients with nonalcoholic fatty liver disease. Clin Sci (Lond). 2004;106:635-43.

96. Gormaz JG, Rodrigo R, Videla LA, Beems M. Biosynthesis and bioavailability of long-chain polyunsaturated fatty acids in non-alcoholic fatty liver disease. Prog Lipid Res. 2010;49(4):407-19.

\section{Publisher's Note}

Springer Nature remains neutral with regard to jurisdictional claims in published maps and institutional affiliations.
Ready to submit your research? Choose BMC and benefit from:

- fast, convenient online submission

- thorough peer review by experienced researchers in your field

- rapid publication on acceptance

- support for research data, including large and complex data types

- gold Open Access which fosters wider collaboration and increased citations

- maximum visibility for your research: over $100 \mathrm{M}$ website views per year

At BMC, research is always in progress.

Learn more biomedcentral.com/submissions 